Research Article

\title{
Effects of Environmental Factors on Ozone Flux over a Wheat Field Modeled with an Artificial Neural Network
}

\author{
Zhilin Zhu $\mathbb{i D}^{1,2}$ \\ ${ }^{1}$ Key Laboratory of Ecosystem Network Observation and Modeling, \\ Institute of Geographic Sciences and Natural Resources Research, Chinese Academy of Sciences, Beijing 100101, China \\ ${ }^{2}$ College of Resources and Environment, University of Chinese Academy of Sciences, Beijing 100049, China
}

Correspondence should be addressed to Zhilin Zhu; zhuzl@igsnrr.ac.cn

Received 24 January 2019; Revised 11 May 2019; Accepted 22 May 2019; Published 4 June 2019

Academic Editor: Ilan Levy

Copyright (c) 2019 Zhilin Zhu. This is an open access article distributed under the Creative Commons Attribution License, which permits unrestricted use, distribution, and reproduction in any medium, provided the original work is properly cited.

\begin{abstract}
Ozone $\left(\mathrm{O}_{3}\right)$ flux-based indices are considered better than $\mathrm{O}_{3}$ concentration-based indices in assessing the effects of ground $\mathrm{O}_{3}$ on ecosystem and crop yields. However, $\mathrm{O}_{3}$ flux $\left(F_{\mathrm{o}}\right)$ measurements are often lacking due to technical reasons and environmental conditions. This hampers the calculation of flux-based indices. In this paper, an artificial neural network (ANN) method was attempted to simulate the relationships between $F_{\mathrm{o}}$ and environmental factors measured over a wheat field in Yucheng, China. The results show that the ANN-modeled $F_{\mathrm{o}}$ values were in good agreement with the measured $F_{\mathrm{o}}$ values. The $R^{2}$ of an ANN model with 6 routine independent environmental variables exceeded 0.8 for training datasets, and the RMSE and MAE were $3.074 \mathrm{nmol} \cdot \mathrm{m}^{-2} \cdot \mathrm{s}$ and $2.276 \mathrm{nmol} \cdot \mathrm{m}^{-2} \cdot \mathrm{s}$ for test dataset, respectively. $\mathrm{CO}_{2}$ flux and water vapor flux have strong correlations with $F_{\mathrm{o}}$ and could improve the fitness of ANN models. Besides the combinations of included variables and selection of training data, the number of neurons is also a source of uncertainties in an ANN model. The fitness of the modeled $F_{\mathrm{o}}$ was sensitive to the neuron number when it ranged from 1 to 10. The ANN model consists of complex arithmetic expressions between $F_{\mathrm{o}}$ and independent variables, and the response analysis shows that the model can reflect their basic physical relationships and importance. $\mathrm{O}_{3}$ concentration, global radiation, and wind speed are the important factors affecting $\mathrm{O}_{3}$ deposition. ANN methods exhibit significant value for filling the gaps of $F_{\mathrm{o}}$ measured with micrometeorological methods.
\end{abstract}

\section{Introduction}

In an atmospheric column, approximately $90 \%$ of total ozone $\left(\mathrm{O}_{3}\right)$ exists in the stratospheric $\mathrm{O}_{3}$ layer and protects Earth's surface from excessive UV radiation. This category of $\mathrm{O}_{3}$ is therefore referred to as "good" ozone [1]. However, the troposphere $\mathrm{O}_{3}$ can negatively affect vegetation tissues, photosynthesis, and crop yields [2]. The tropospheric $\mathrm{O}_{3}$ mainly results from the in situ photochemical production, and a small portion is transported from the stratosphere [3]. $\mathrm{O}_{3}$ destruction involves chemical decomposition and deposition on Earth's surface. The total $\mathrm{O}_{3}$ deposition can be quantitatively reflected by measured $\mathrm{O}_{3}$ flux $\left(F_{\mathrm{o}}\right)$, and its magnitude and variations can facilitate understanding of the $\mathrm{O}_{3}$ deposition processes.
The quantitative assessment of the effects of ground $\mathrm{O}_{3}$ on ecosystem and crop yield loss in a region requires selection of an assessment model and calculation of the corresponding assessment index, and the calculation of assessment indices requires continuous measurement of $\mathrm{O}_{3}$ concentration or flux $[4,5]$. The concentration-based indices do not consider the status of vegetation and ecosystems (e.g., stomatal conductance and leaf area index). Many studies have shown that $\mathrm{O}_{3}$-reduced yield loss is more closely related to the stomatal $\mathrm{O}_{3}$ flux [5-7].

Gerosa et al. [8] presented a method of estimating $\mathrm{O}_{3}$ stomatal flux by partitioning total $F_{\mathrm{o}}$. Briefly, $\mathrm{O}_{3}$ stomatal resistance was obtained by converting vapor stomatal resistance (Penman-Monteith approach), and the $\mathrm{O}_{3}$ concentration near the canopy was calculated using the resistance 
model, which needs the total $\mathrm{O}_{3}$ flux. So, measuring total $F_{\mathrm{o}}$ is the first step in estimating stomatal $\mathrm{O}_{3}$ flux [9]. $F_{\mathrm{o}}$ is usually measured by micrometeorological methods, and the eddy covariance (EC) method is considered the most direct fluxmeasuring method $[8,10-12]$. However, due to a lack of high performance fast-response $\mathrm{O}_{3}$ analyzers (e.g., it needs to change $\mathrm{O}_{3}$-sensitive dye often and its sensitivity is unstable), EC-measured $\mathrm{O}_{3}$ flux has many temporal gaps in the associated datasets $[8,13,14]$. This leads to difficulties in calculating the value of $\mathrm{a} \mathrm{O}_{3}$ stomatal flux-based index using the EC $\mathrm{O}_{3}$ flux since the effect of $\mathrm{O}_{3}$ on crop yields results from the accumulation of $\mathrm{O}_{3}$ damage. Therefore, it is necessary to find a method of filling the gaps in $\mathrm{O}_{3}$ flux datasets.

The gap-filling methods for ecosystem $\mathrm{CO}_{2}$ flux have been summarized in the literature $[15,16]$. However, there have not been investigations into methods for filling gaps in $F_{\mathrm{o}}$ data. As the controlling factors for $\mathrm{O}_{3}$ flux are more complex, it is difficult to produce physically based equations to reflect the $F_{\mathrm{o}}$ and environmental variables under any conditions. Although some mechanism-based models (typically a resistance-in-series) have been developed, many parameters must be empirically estimated based on the specific site or type of vegetation $[17,18]$.

Artificial neural networks (ANN), as an artificial intelligence using machine learning techniques, have been applied for approximation, prediction, classification, modeling, and data gap-filling in many scientific disciplines [16, 19-21]. ANN is able to learn from training data and to represent the nonlinearity between the dependent and independent variables. It is suitable for simulating empirical datasets with complex and nonlinear relationships between variables and dependent variable(s). It is particularly useful when it is difficult to express these relationships using one or more simple equations. Compared to physically based models, ANNs have more success in simulating complex processes with a high precision without any analytical models [22-24]. These attributes make ANNs a good candidate for attempts at filling gaps in $\mathrm{O}_{3}$ flux data. In addition, a sensitivity analysis can be conducted by analyzing the response curves of the different input variables that are created by fixing all other input variables at a certain value $[25,26]$. For gap filling of $F_{\mathrm{o}}$, ANN modeling is also a practical and simple method [16].

ANN methods have been used widely to model and predict $\mathrm{O}_{3}$ concentration $[27,28]$ and $\mathrm{CO}_{2}$ fluxes $[21,29,30]$. However, the ANN approach has not been used to simulate $\mathrm{O}_{3}$ flux variation with other factor fluxes or meteorological factors. The objectives of this study are to (1) develop a series of ANN models to simulate the relationship between $F_{\mathrm{o}}$ and environmental variables; (2) determine the optimal ANN model to simulate $F_{\mathrm{o}}$ for interpolation of measured $F_{\mathrm{o}}$; and (3) analyze the responses and relative importance of different environmental variables to $\mathrm{O}_{3}$ flux.

\section{Materials and Methods}

2.1. Site and Observations. The observations were carried out over a winter wheat field at the Yucheng Comprehensive Experiment Station of the Chinese Academy of Sciences $\left(36^{\circ} 50^{\prime} \mathrm{N}, 116^{\circ} 34^{\prime} \mathrm{E} ; 28 \mathrm{~m}\right.$ a.s.l.; Shandong Province, China).
The site is located in the Northwest-Shandong plain, characterized by loamy soil texture and semiarid and warm temperate climate. The experimental site is very flat, and the fetch requirements for EC measurements are met. The study period of the field experiment covered entire growing season of wheat (from 2 March to 6 June 2012).

The ambient $\mathrm{O}_{3}$ concentration was measured with a slowresponse UV absorption-based $\mathrm{O}_{3}$ analyzer (Model 205, 2B Technologies Inc., USA). The $\mathrm{O}_{3}$ flux was measured with the eddy covariance method in combination with observations of $\mathrm{CO}_{2}, \mathrm{H}_{2} \mathrm{O}$, and sensible heat fluxes. These variables were measured with a 3D sonic anemometer (CSAT3, Campbell Scientific Instrument, USA) and an open-path $\mathrm{CO}_{2} / \mathrm{H}_{2} \mathrm{O}$ gas analyzer (LI-7500, LI-COR Biosciences, USA). The $\mathrm{O}_{3}$ fluctuation was measured with a fast-response $\mathrm{O}_{3}$ analyzer developed by Enviscope $\mathrm{GmbH}$ [31] (hereafter referred to as ENVI). Micrometeorological and radiation variables measurements include air temperature and relative humidity (HMP45C; Vaisala Co., Finland), wind speed (A100R; Vector Instruments, UK), net radiation (CNR1; Kipp and Zonen, the Netherlands), and photosynthetically active radiation (LI190SB; LI-COR, USA). All sensors were installed at $2.2 \mathrm{~m}$ height. Because of the continuous consumption of organic dye, the sensitivity of the ENVI slowly decreased with time. To maintain high sensitivity in the ENVI, we replaced the organic dye disc every 3 to 4 days. Raw data from the EC system were recorded at $10 \mathrm{~Hz}$, and 30 -minute mean data were recorded by a data logger (CR3000, Campbell Sci., USA).

2.2. $\mathrm{O}_{3}$ Flux Calculation. Since the fast-response $\mathrm{O}_{3}$ analyzer's sensitivity is not constant [14], the sensitivity must be calibrated by a slow-response $\mathrm{O}_{3}$ concentration analyzer. However, it has been shown that the sensitivity can be treated as constant when using a $30 \mathrm{~min}$ averaging interval [32]. This means that the ENVI's output $X$ (in $\mathrm{mV}$ ) is proportional to the absolute ambient $\mathrm{O}_{3}$ concentration over a 30 min period. Based on this assumption, the $\mathrm{O}_{3}$ deposition velocity $\left(V_{\mathrm{d}}\right)$, defined as the $\mathrm{O}_{3}$ flux divided by $\mathrm{O}_{3}$ concentration, can be calculated by the following equation [33]:

$$
V_{\mathrm{d}}=-\frac{F_{\mathrm{o}}}{\overline{\rho_{\mathrm{o}}}}=-\frac{\overline{w^{\prime} V_{\mathrm{G}}^{\prime}}}{\overline{V_{\mathrm{G}}}}
$$

where $\rho_{\mathrm{o}}$ is the $\mathrm{O}_{3}$ mass density (or concentration; $\mu \mathrm{g} \cdot \mathrm{m}^{-3}$ ), $w$ is the vertical wind speed $\left(\mathrm{m} \cdot \mathrm{s}^{-1}\right)$, and $V_{G}$ is the output signal $(\mathrm{mV})$ of the fast-response $\mathrm{O}_{3}$ analyzer. The overbar denotes the time average, and the primes indicate the temporal fluctuation of each variable. The $\mathrm{O}_{3}$ vertical turbulent flux $F_{\mathrm{o}}\left(\mu \mathrm{g} \cdot \mathrm{s}^{-1} \cdot \mathrm{m}^{-2}\right)$ between atmosphere and surface is calculated by the following equation:

$$
F_{\mathrm{o}}=-\overline{\rho_{\mathrm{o}}} V_{\mathrm{d}}=\frac{P}{T} \frac{M_{\mathrm{o} 3}}{R} \frac{\overline{x_{\mathrm{o}}}}{\overline{V_{\mathrm{G}}}} \overline{w^{\prime} V_{\mathrm{G}}^{\prime}},
$$

where $x_{\mathrm{o}}$ is the mean $\mathrm{O}_{3}$ mixing ratio (ppb) measured by the slow-response $\mathrm{O}_{3}$ analyzer, $P$ is the barometric pressure $\left(\mathrm{N} \cdot \mathrm{m}^{-2}\right), T$ is the air temperature $(\mathrm{K}), R$ is the universal gas constant $\left(8.314 \mathrm{~J} \cdot \mathrm{mol}^{-1} \cdot \mathrm{K}^{-1}\right)$, and $M_{\mathrm{o} 3}$ is the molar mass of $\mathrm{O}_{3}$ $\left(48.0 \mathrm{~g} \cdot \mathrm{mol}^{-1}\right)$. 
In practice, all fluxes were calculated by EddyPro ${ }^{\circledR}$ software with a series of corrections. Double rotation was utilized to correct tilt errors [34]. $\mathrm{O}_{3}$ flux loss caused by time delay was corrected by the maximum covariance method [35]. Only the effect of density variation caused by water vapor on $\mathrm{O}_{3}$ flux was considered $[14,36]$. The more detailed description of observations, calculations, and corrections can be found in Zhu et al. [14].

2.3. Artificial Neural Network Modeling. In a general model, variable(s) and the independent variable can be expressed as one or more analytical expression(s). In contrast, artificial neural networks (ANNs) are capable of recognizing and simulating complex relations without any analytical expression(s) of variables and outputs. The relation is produced by the ANN that has been trained. Although there are many types of ANN (e.g., Hopfield networks and Kohonen networks) and many algorithms to be used to train ANN, the feedforward network (FFN) with backpropagation (BP) algorithm is the most popular and has been used in more than other types of neural networks for a wide variety of problems [26, 37-40]. The feedforward BP networks have a simple structure for simulating complex systems, and its structure is sufficiently robust to simulate many nonlinear systems $[27,41]$. Therefore, the BP network was used in the study. Figure 1 shows a schematic of the three-layer BP network. The nonlinear elements or neurons are arranged in successive layers, and the information flows from input layer to output layer through the hidden layers. The number of inputs depends on the model performance, and theoretically, more inputs increase model performance. The hidden layers are another important parameter in a BP network.

Because of the complexity of the ANN calculation process, the ANN core algorithms used in this study are adopted from the MATLAB software package. However, the ANN requires a prepared dataset and the determination of parameters. The general steps for the setup of the BP network and parameters are described as follows:

(1) The determination of independent variables $\left(X_{\mathrm{i}}, i=1\right.$, $2, \ldots, n)$. Although ANNs do not require the specification of dependent variables and independent variables, variables should have a certain relationship in terms of mechanism(s) or variation patterns. Based on the previous studies and observed items, we attempt to build a series of ANN models. These models have different combinations of input variables to determine the most relevant input variables for modeling $\mathrm{O}_{3}$ flux. The input variables include micrometeorological variables, radiation values, and fluxes.

(2) The determination of the number of nodes or "neurons" in the hidden layer. This is related to experience or examinations. In general, this number should be larger than the number of $X_{i}$.

(3) The generation of a network by training. The training dataset and parameters are the keys to generate a

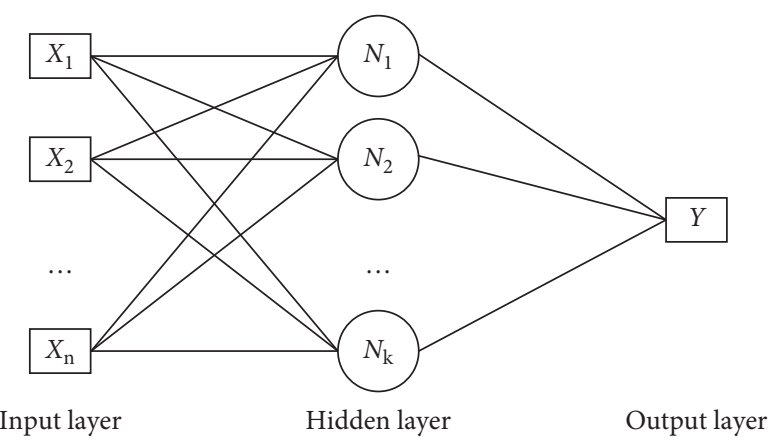

FIgURE 1: Schematic of a three-layer backpropagation artificial neural network.

good BP network. The training dataset must be representative and of high quality, and the parameters should be suitable. The training process will determine a set of optimal weights and biases. Although there are different transfer functions, such as linear function and a threshold function [38], sigmoid transfer function is the most popular choice for many studies [40]. This transfer function was also used for the neurons in the hidden layer. Using the MATLAB software package, the weights and biases in the ANN are obtained in an iterative calibration process based on the Levenberg-Marquardt (LM) algorithm. The root-mean-squared error is used to monitor the performance of modeling. Normally, the validation error decreases during the initial phase of training and begins to rise when the network begins to overfit the data. To avoid overfitting, the weights and biases of the network can be automatically saved when the validation error reaches a minimum.

(4) The evaluation of the ANN model using training and test datasets. In this study, three statistical parameters, i.e., root-mean-squared error (RMSE), mean absolute error (MAE), and coefficient of determination $\left(R^{2}\right)$, were used to evaluate the performance of models. RMSE and MAE present information about the degree of accuracy of an ANN model, and $R^{2}$ measures the degree of the linear relationship between measured and modeled $\mathrm{O}_{3}$ fluxes.

The three parameters were calculated with the following equations:

$$
\begin{aligned}
\text { RMSE } & =\sqrt{\left[\frac{1}{N} \sum_{i=1}^{N}\left(Y_{i}-F_{i}\right)^{2},\right.} \\
\text { MAE } & =\frac{1}{N} \sum_{i=1}^{N}\left|Y_{i}-F\right|, \\
R^{2} & =\frac{\left[\sum\left(Y_{i}-\bar{Y}\right)\left(F_{i}-\bar{F}\right)\right]^{2}}{\sum\left(Y_{i}-\bar{Y}\right) \sum\left(F_{i}-\bar{F}\right)},
\end{aligned}
$$


where $Y_{\mathrm{i}}$ and $F_{\mathrm{i}}$ are the simulated and measured $\mathrm{O}_{3}$ flux, respectively; the overbar denotes the average of each variables, and $N$ is the sample number.

2.4. Dataset Preparation. To create a satisfactory ANN model, a high-quality dataset is very important. Due to different reasons, all variables, especially the measured $\mathrm{O}_{3}$ flux, presented many low quality or erroneous data. In this study, the selected data for training and testing satisfy the conditions as follows. Approximately $58.5 \%$ of the total data points in the set are low quality or erroneous, and they were filtered using the following metrics.

(1) Only daytime data were adopted. During nighttime, $\mathrm{O}_{3}$ concentration is generally low and wheat stomata are closed, and the effect of $\mathrm{O}_{3}$ on wheat can be ignored. Nighttime fluxes also exhibit a significant amount of inaccuracies because of weak turbulence [42].

(2) Ozone fluxes are between $-40 \mathrm{nmol} \cdot \mathrm{m}^{-2} \cdot \mathrm{s}^{-1}$ and $0 \mathrm{nmol} \mathrm{m}{ }^{-2} \cdot \mathrm{s}^{-1}$. As $\mathrm{O}_{3}$ is always deposited downward on the surface, the positive $\mathrm{O}_{3}$ fluxes represent errors. The initial threshold value of $-40 \mathrm{nmol} \cdot \mathrm{m}^{-2} \cdot \mathrm{s}^{-1}$ was empirically determined via the time series of $\mathrm{O}_{3}$ flux. Moreover, the threshold was variable based on the wheat status. For example, the threshold was set to $-20 \mathrm{nmol} \cdot \mathrm{m}^{-2} \cdot \mathrm{s}^{-1}$ in the first stage of wheat. In addition, some rapid spikes of $\mathrm{O}_{3}$ flux were deemed unlikely based on the underlying mechanisms. These data points were deleted even though they did not exceed the threshold value.

(3) The data of all inputs at a time are completed. Some input variables, especially the turbulent fluxes, have errors or gaps due to various reasons. To keep training data consistent, these data were also excluded.

Finally, 1402 data points ( $41.5 \%$ of total $\mathrm{O}_{3}$ flux data) were used to train and validate all ANN models. Half of the high-quality dataset (701 data points) was selected for ANN training, and the other half of-high quality data were used for the test dataset. According to the MATLAB software manual, the training dataset is randomly divided into three subsets, i.e., the training set, the validation set, and the test set. Their ratios are $70 \%, 15 \%$, and $15 \%$, and the corresponding data points are 491,105 , and 105 , respectively. The training set is used for computing the gradient as well as updating the network weights and biases. The validation set is used to validate the ANN performance, and the test set is used to compare different models.

\section{Results and Discussion}

3.1. Input Variables Choice and Its Performances. Although an ANN model is only dependent on the mathematical relations of inputs and outputs, variables that are irrelevant or lack a physical basis should be excluded. Based on equation (1), $\mathrm{O}_{3}$ flux is the product of $\mathrm{O}_{3}$ concentration and deposition velocity $\left(V_{\mathrm{d}}\right)$. For $\mathrm{O}_{3}$ concentration, the production and decomposition result from a series of complex chemical and physical processes. The local $\mathrm{O}_{3}$ concentration variation mainly depends on its precursors (e.g., VOCs and $\mathrm{NO}_{x}$ ), long-range transport and a subset of environmental factors, such as radiation, temperature, and humidity [43-45]. $V_{\mathrm{d}}$ is affected to a certain extent by atmospheric turbulence intensity and underlying surface conditions, such as wind speed, friction speed, soil moisture, $\mathrm{O}_{3}$-reactive chemicals, and vegetation status [46-48].

Due to a lack of observations for $\mathrm{O}_{3}$-reactive chemicals, only some micrometeorological and radiation variables were selected to model $F_{\mathrm{o}}$ variation in this study. The initial input variables for attempting to model $F_{\mathrm{o}}$ include $\mathrm{O}_{3}$ concentration $\left(C_{\mathrm{O}_{3}}\right)$, global radiation $(Q)$, air temperature $\left(T_{\mathrm{a}}\right)$, relative humidity $(\mathrm{RH})$, wind speed $(U)$, and soil water content $\left(S_{\mathrm{W}}\right)$. In addition, $\mathrm{O}_{3}$ flux access to stomata is coupled with the $\mathrm{CO}_{2}$ flux $\left(F_{\mathrm{c}}\right)$ and water vapor fluxes (LE). These two fluxes are also deployed in our attempts to model $F_{\mathrm{o}}$. Because of the high correlation between the mean diurnal pattern of many variables and time [30], the effect of time $\left(T_{\mathrm{m}}\right)$ on the ANN model was also investigated in this study.

To test the dependency of each variable on $\mathrm{O}_{3}$ flux, the $\mathrm{O}_{3}$ flux with one variable was first simulated, and then, $\mathrm{O}_{3}$ flux with different variable combinations were simulated. Table 1 presents the statistics for each variable and variable combinations. For any single micrometeorological variable, the RMSE values exceed $5 \mathrm{ng} \cdot \mathrm{m}^{-2} \cdot \mathrm{s}^{-1}$ and all $R^{2}$ values are less than 0.4. This means that any single variable cannot accurately model $\mathrm{O}_{3}$ flux. Among these variables, $\mathrm{O}_{3}$ concentration and radiation have relatively strong correlations. For other turbulent fluxes (LE, $F_{\mathrm{c}}$ ), ANN-modeled $F_{\mathrm{o}}$ values were strongly correlated with $F_{\mathrm{c}}$ and LE, but modeled $F_{\mathrm{o}}$ values were weakly correlated with sensible heat flux $(H)$. This highlights the fact that $\mathrm{O}_{3}$ flux is mainly affected by the stomata flux, as stomata are the main pathway of LE and $F_{c}$. Although these fluxes have similar diurnal patterns, $F_{\mathrm{c}}$ and LE cannot be considered as the driving factors of $\mathrm{O}_{3}$ deposition. The $\mathrm{O}_{3}$ deposition process is complex, and changes in the process are mainly driven by many meteorological or environmental factors.

To obtain an optimal ANN model, we attempted to build more ANN models with different combinations of input variables. The combinations can be divided into two classes. Class 1 combinations only consist of routine micrometeorological and radiation factors $\left(T_{\mathrm{a}}, \mathrm{RH}, U, Q, S_{\mathrm{W}}\right.$, and $\left.C_{\mathrm{O}_{3}}\right)$, i.e., models T11 to T15 in Table 1. Meanwhile, we also tested the effect of time (T16). The variables in Class 1 are easy to observe and possess sufficiently high accuracy. The combinations can increase the fitness of observed and ANNmodeled $F_{\mathrm{o}}$, even if the combination only uses meteorological variables (T12). Class 2 combinations add the turbulent fluxes $\left(H, F_{\mathrm{c}}\right.$, and LE) in addition to the variables in Class 1, i.e., models T17 to T20 in Table 1. Although the correlation levels increase slightly in Class 2 models when compared to the models of Class 1 , the effect of these fluxes on $F_{\mathrm{o}}$ gap filling is very limited. When there is a gap in $F_{\mathrm{o}}$ data, other fluxes ( $F_{c}$ and LE) often exhibit simultaneous gaps in their observational datasets. Meanwhile, the flux data have lower accuracies than the micrometeorological and 
TABLE 1: Statistics for each ANN model with training dataset and test dataset.

\begin{tabular}{|c|c|c|c|c|c|c|c|}
\hline \multirow{2}{*}{ Model } & \multirow{2}{*}{ Inputs and combinations } & \multicolumn{3}{|c|}{ Training dataset } & \multicolumn{3}{|c|}{ Test dataset } \\
\hline & & $\operatorname{RSME}\left(\mathrm{nmol} \cdot \mathrm{m}^{-2} \cdot \mathrm{s}\right)$ & $\operatorname{MAE}\left(\mathrm{nmol} \cdot \mathrm{m}^{-2} \cdot \mathrm{s}\right)$ & $R^{2}$ & $\operatorname{RSME}\left(\mathrm{nmol} \cdot \mathrm{m}^{-2} \cdot \mathrm{s}\right)$ & $\operatorname{MAE}\left(\mathrm{nmol} \cdot \mathrm{m}^{-2} \cdot \mathrm{s}\right)$ & $R^{2}$ \\
\hline $\mathrm{T} 1$ & $T_{\mathrm{a}}$ & 5.391 & 4.119 & 0.282 & 5.578 & 4.305 & 0.234 \\
\hline $\mathrm{T} 2$ & $\mathrm{RH}$ & 6.251 & 4.780 & 0.062 & 6.252 & 4.808 & 0.059 \\
\hline T3 & $U$ & 5.897 & 4.495 & 0.141 & 5.974 & 4.558 & 0.123 \\
\hline $\mathrm{T} 4$ & $Q$ & 5.339 & 4.044 & 0.301 & 5.607 & 4.226 & 0.237 \\
\hline T5 & $S_{\mathrm{W}}$ & 6.091 & 4.589 & 0.109 & 6.183 & 4.683 & 0.090 \\
\hline T6 & $C_{\mathrm{O}_{3}}$ & 5.182 & 3.836 & 0.338 & 5.394 & 4.015 & 0.287 \\
\hline T7 & $H^{3}$ & 6.229 & 4.786 & 0.040 & 6.537 & 4.887 & 0.009 \\
\hline T8 & $\mathrm{LE}$ & 4.273 & 3.289 & 0.551 & 4.731 & 3.591 & 0.461 \\
\hline T9 & $F_{\mathrm{c}}$ & 5.075 & 3.678 & 0.381 & 5.496 & 4.035 & 0.294 \\
\hline $\mathrm{T} 10$ & $T_{\mathrm{m}}$ & 5.817 & 4.326 & 0.171 & 5.831 & 4.295 & 0.163 \\
\hline T11 & $T_{\mathrm{a}} \mathrm{RH}$ & 5.205 & 3.864 & 0.330 & 5.365 & 4.045 & 0.289 \\
\hline $\mathrm{T} 12$ & $T_{\mathrm{a}} \mathrm{RH} U$ & 4.013 & 3.033 & 0.604 & 4.177 & 3.172 & 0.571 \\
\hline $\mathrm{T} 13$ & $T_{\mathrm{a}} \mathrm{RH} U \mathrm{Q}$ & 3.723 & 2.792 & 0.659 & 3.929 & 2.926 & 0.621 \\
\hline $\mathrm{T} 14$ & $T_{\mathrm{a}} \mathrm{RH} U Q S_{\mathrm{W}}$ & 3.569 & 2.667 & 0.685 & 3.752 & 2.798 & 0.652 \\
\hline T15 & $T_{\mathrm{a}} \mathrm{RH} U Q S_{\mathrm{W}} C_{\mathrm{O}_{3}}$ & 2.662 & 1.971 & 0.827 & 3.074 & 2.276 & 0.767 \\
\hline T16 & $T_{\mathrm{a}} \mathrm{RH} U Q S_{\mathrm{W}} C_{\mathrm{O}_{3}} T_{\mathrm{m}}$ & 2.652 & 1.967 & 0.829 & 3.021 & 2.215 & 0.783 \\
\hline $\mathrm{T} 17$ & $T_{\mathrm{a}} \mathrm{RH} U Q S_{\mathrm{W}} C_{\mathrm{O}_{3}} H$ & 2.460 & 1.813 & 0.855 & 2.844 & 2.055 & 0.805 \\
\hline $\mathrm{T} 18$ & $T_{\mathrm{a}} \mathrm{RH} U Q S_{\mathrm{W}} C_{\mathrm{O}_{3}} \mathrm{LE}$ & 2.448 & 1.812 & 0.855 & 2.834 & 2.079 & 0.809 \\
\hline $\mathrm{T} 19$ & $T_{\mathrm{a}} \mathrm{RH} U Q S_{\mathrm{W}} C_{\mathrm{O}_{3}} F_{\mathrm{c}}$ & 2.254 & 1.671 & 0.875 & 2.763 & 1.997 & 0.814 \\
\hline $\mathrm{T} 20$ & $T_{\mathrm{a}} \mathrm{RH} U Q S_{\mathrm{W}} C_{\mathrm{O}_{3}} \mathrm{LE} F_{\mathrm{c}}$ & 2.310 & 1.662 & 0.881 & 2.697 & 1.917 & 0.839 \\
\hline
\end{tabular}

radiation variables. Among the two classes of combinations, we select T15 and T20 as examples to analyze their performances as well as the contributions and responses of each variable to $\mathrm{O}_{3}$ flux.

Figure 2 shows a scatter plot of measured and modeled $\mathrm{O}_{3}$ fluxes using ANN models T15 and T20 for the training dataset and test dataset. The modeled $\mathrm{O}_{3}$ fluxes in these two models match the measured $\mathrm{O}_{3}$ flux to a high degree. There are not obvious deviations from the $1: 1$ line. Although the first model contains only six routine variables (no turbulent fluxes), the model produced an $R^{2}$ of 0.826 and 0.767 for the training dataset and test dataset, respectively. The fitness of model T20 is marginally superior to the fitness of T15. The $R^{2}$ values of T20 are 0.881 and 0.839 for the training dataset and test dataset, respectively. The $R^{2}$ can be interpreted as the ratio of the variances for the modeled flux and the real flux.

3.2. Effect of ANN Schema on the Model Performance. In addition to the selection of variable combinations, the training data quality and architecture parameters also affect the performance of an ANN model. The ANN model can be considered as a black-box, so the performance is strongly dependent on the training dataset quality. Network architecture consists of numbers of layers, number of nodes, and weight calculation method. Generally, greater numbers of layers and nodes produce better performance. However, to avoid overtraining, the ANN training process requires an appropriate learning rate (weight adjustment steps) and a stopping criterion [16].

Compared to other types of statistical models, ANN models are difficult to replicate. Even if the same dataset and parameters are used, there are slight differences in the modeled results between different runs. The results after training vary slightly because the neural network is initialized with random weights. As an example, Figure 3 shows the daily variations of $\mathrm{O}_{3}$ flux measured on May 12 with EC method and ANN modeled with T15. It is clear that the ANN modeled $F_{\mathrm{o}}$ each run are different, and they are around the measured $F_{\mathrm{o}}$. To mitigate these uncertainties, we calculated the average of 10 runs with the same variables combinations and parameters to generate the modeled $\mathrm{O}_{3}$ flux. Table 2 compares the statistics of ANN-modeled $F_{\mathrm{o}}$ with T15. As shown, statistical indicators of 10-run-averaged are better than separate indicators. The RMSE and MAE are the smallest, and the $R^{2}$ is the largest.

Another problem that arises in ANN modeling is socalled overtraining or overfitting. An overtrained network cannot learn the general traits that exist in the training set, and the network will lose the capacity to generalize. Three important parameters can be used to avoid this phenomenon: the number of hidden layers, the number of epochs, and the number of neurons in each hidden layer. Although these parameters are crucial to a model, there are no definite rules on how to determine them. In the ANN package of the MATLAB software, the number of hidden layers and the number of neurons in each hidden layer can be assigned. To decrease the number of ANN parameters, a feedforward network with one hidden layer and a sufficient number of neurons was used in this study. This satisfies any finite inputoutput statistical modeling [41]. The optimal number of epochs (iterations) can be determined automatically by the software based on the best performances. Therefore, only the optimum neurons should be determined by testing the performance of an ANN model with different neurons.

Figure 4 shows the variations of MAE, RMSE, and $R^{2}$ for the models T15 and T20 as the number of neurons change. It can be seen that the MAE and RMSE of the two ANN models rapidly decrease when the number of neurons changes from 1 to 10 , and then the variations are slower and more stable. 


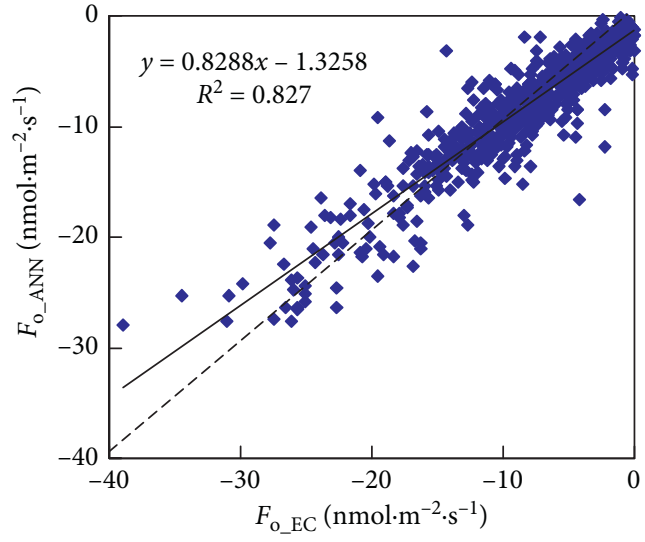

(a)

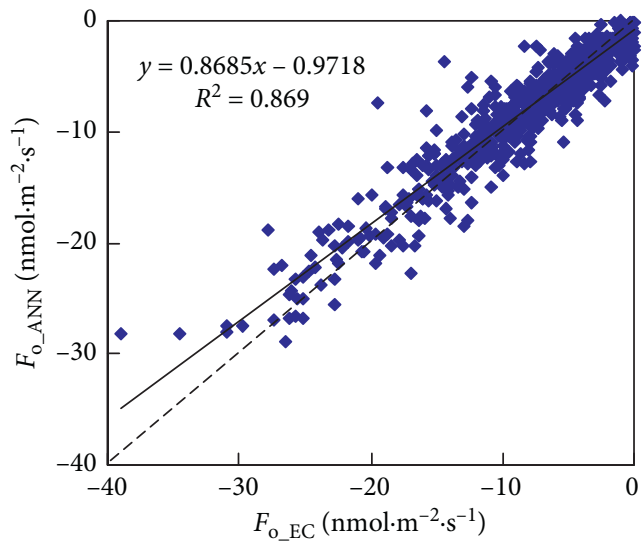

(c)

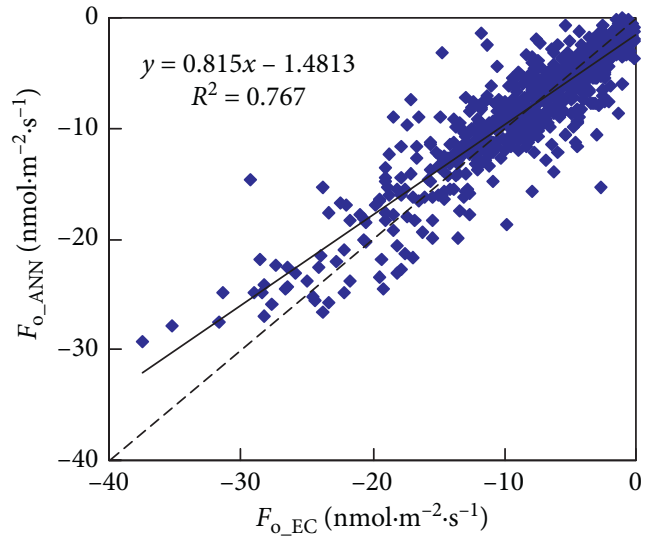

(b)

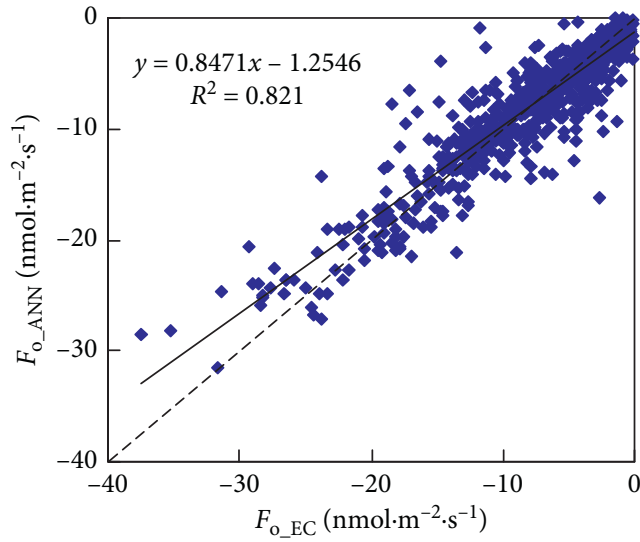

(d)

Figure 2: Observed versus simulated ozone flux with models T15 and T20, respectively. (a) Model T15 with the training dataset. (b) Model T15 with the test dataset. (c) Model T20 with the training dataset. (d) Model T20 with the test dataset.

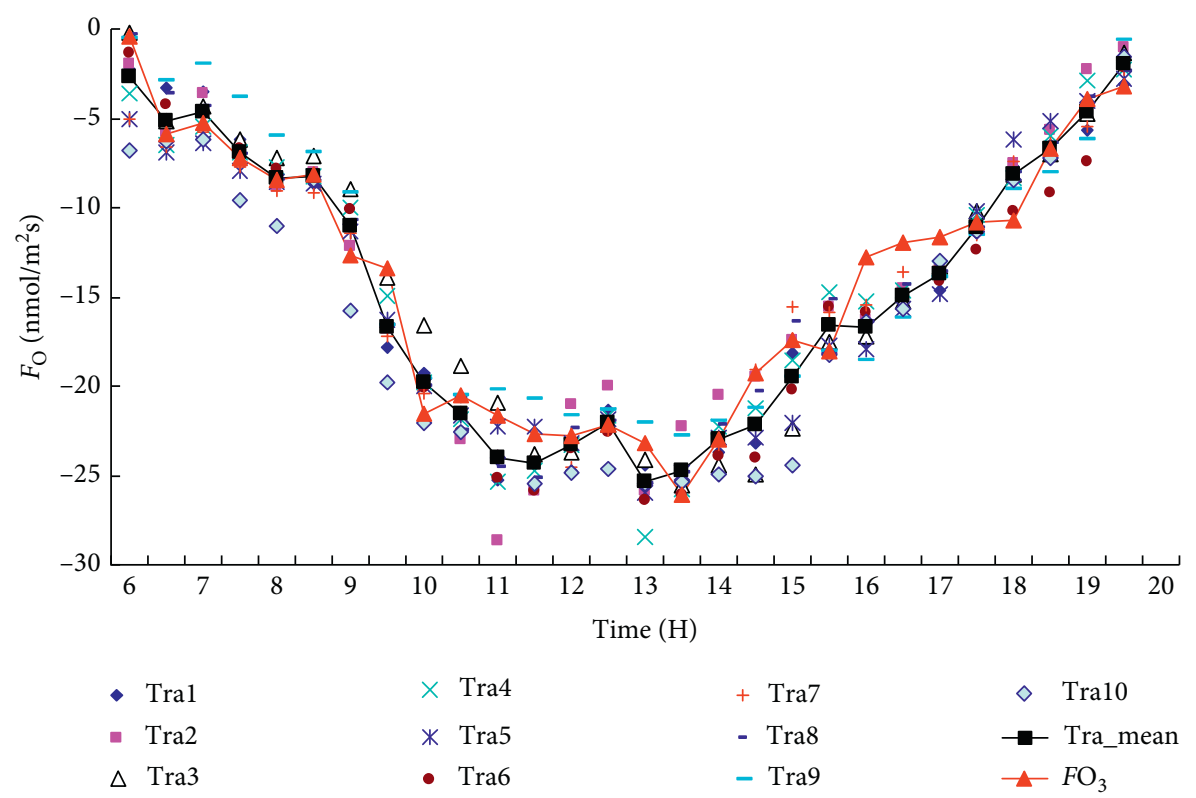

Figure 3: Comparison of diurnal variations of ozone flux measured on May 12 with the EC method $\left(F_{\mathrm{O}_{3}}\right)$ and 10-run ANN modeled with T15. Tra_mean is the mean of 10 runs in the ANN model of $F_{\mathrm{o}}$. 
TABLE 2: Comparison of statistics of $F_{\mathrm{o}}$ values from measurements and the ANN model (T15) in 10 separate runs.

\begin{tabular}{|c|c|c|c|c|c|c|c|c|c|c|c|}
\hline & Tra1 & Tra2 & Tra3 & Tra4 & Tra5 & Tra6 & Tra7 & Tra8 & Tra9 & Tra10 & T_mean \\
\hline RMSE $\left(\mathrm{nmol} \cdot \mathrm{m}^{-2} \cdot \mathrm{s}\right)$ & 2.861 & 2.715 & 2.829 & 2.738 & 2.837 & 2.798 & 2.789 & 2.77 & 2.754 & 2.789 & 2.662 \\
\hline $\operatorname{MAE}\left(\mathrm{nmol} \cdot \mathrm{m}^{-2} \cdot \mathrm{s}\right)$ & 2.191 & 2.078 & 2.148 & 2.155 & 2.174 & 2.115 & 2.044 & 2.135 & 2.071 & 2.091 & 1.971 \\
\hline$R^{2}$ & 0.808 & 0.802 & 0.802 & 0.809 & 0.795 & 0.798 & 0.811 & 0.813 & 0.819 & 0.812 & 0.827 \\
\hline
\end{tabular}

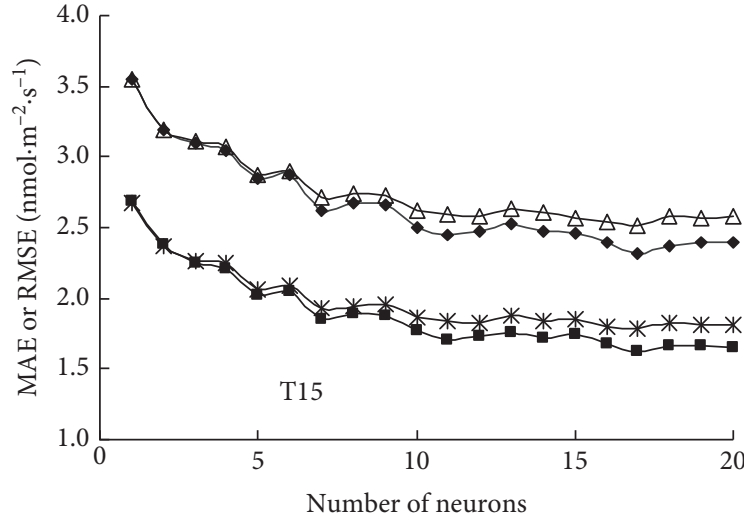

$\rightarrow$ RMSE_train $\triangle$ RMSE_test

$$
\begin{aligned}
& \rightarrow \text { MAE_train } \\
& \rightarrow \text { MAE_test }
\end{aligned}
$$

(a)

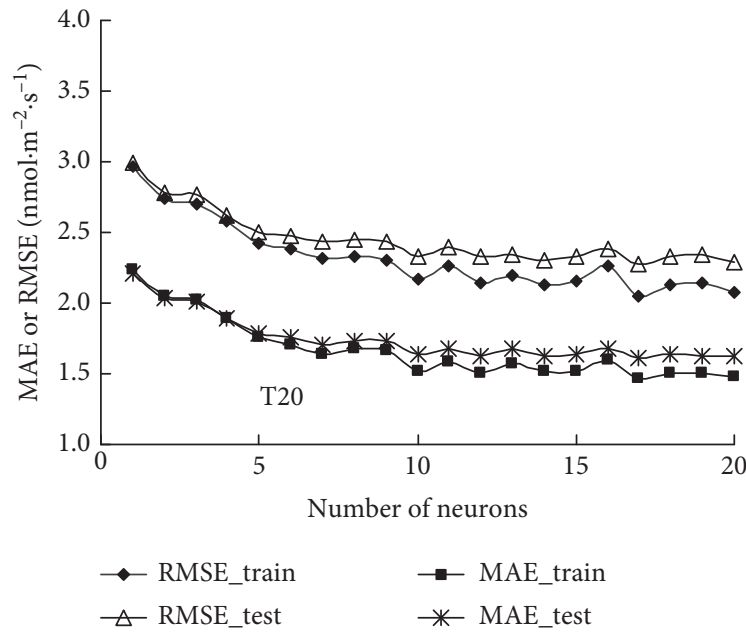

(c)

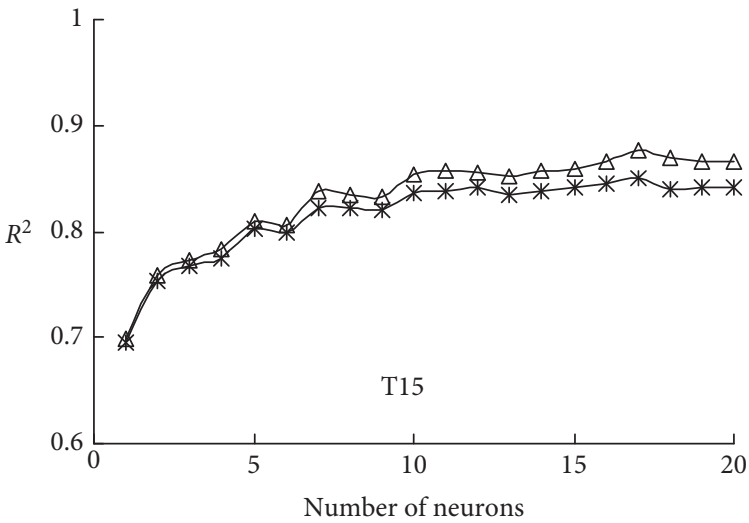

$\triangle R^{2}$ train

* $R^{2}$ _test

(b)

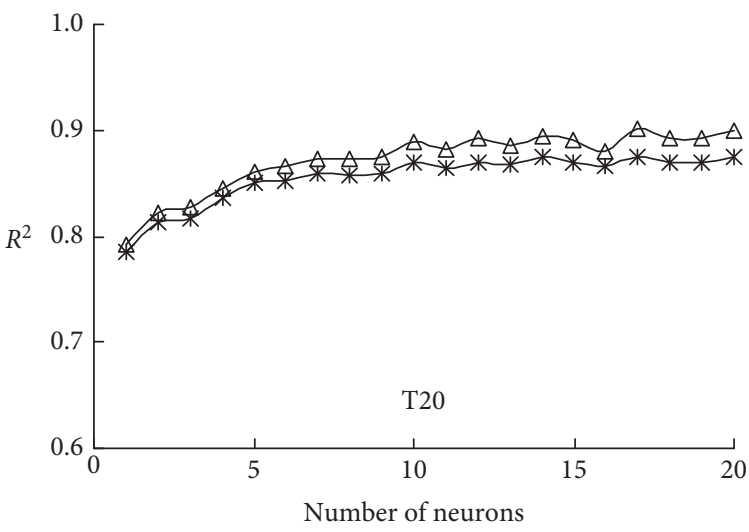

$\triangle R^{2}$ train

* $R^{2}$ _test

(d)

FIgURE 4: Variations of MAE, RMSE, and $R^{2}$ for the models T15 and T20 with different numbers of neurons.

The minima for MAE and RMSE appeared when there were 17 neurons. The performance of $R^{2}$ is similar (Figures 4 (b) and $4(\mathrm{~d})$ ). Therefore, the number 17 was determined to be the optimal neuron number for the hidden layer in our analysis.

3.3. Response of $F_{o}$ to Variables Based on ANN Models. All parameters of an ANN model are fixed once training is finished. The responses of an ANN model can be evaluated by varying a single variable within its measured range and keeping other inputs fixed at their mean values [30, 37]. Figure 5 demonstrates the details of how $\mathrm{O}_{3}$ flux varies across the range of all variables within models T15 and T20. The ranges (minimum and maximum) and mean values of each input variables in the training dataset are given in Table 3.

By excluding the effects of turbulent fluxes, the effect of each environmental variable on $F_{\mathrm{o}}$ can be seen more clearly (Figure 5(a)). Positive responses between $\mathrm{O}_{3}$ concentration, temperature, solar radiation, and relative humidity are shown clearly. After considering the effects of turbulent fluxes (Figure 5(b)), the responses of $F_{c}$ and LE are very obvious, whereas the responses of $T_{\mathrm{a}}, \mathrm{RH}$, and $S_{\mathrm{W}}$ are very weak. Moreover, $\mathrm{O}_{3}$ flux shows a unidirectional variation with most variables, such as $\mathrm{O}_{3}$ concentration, wind speed, temperature, and humidity. Nevertheless, the variation of $F_{\mathrm{o}}$ with soil water content $\left(S_{\mathrm{W}}\right)$ shows a different pattern (Figure 5(a)) $\mathrm{O}_{3}$ deposition decreased when soil water 


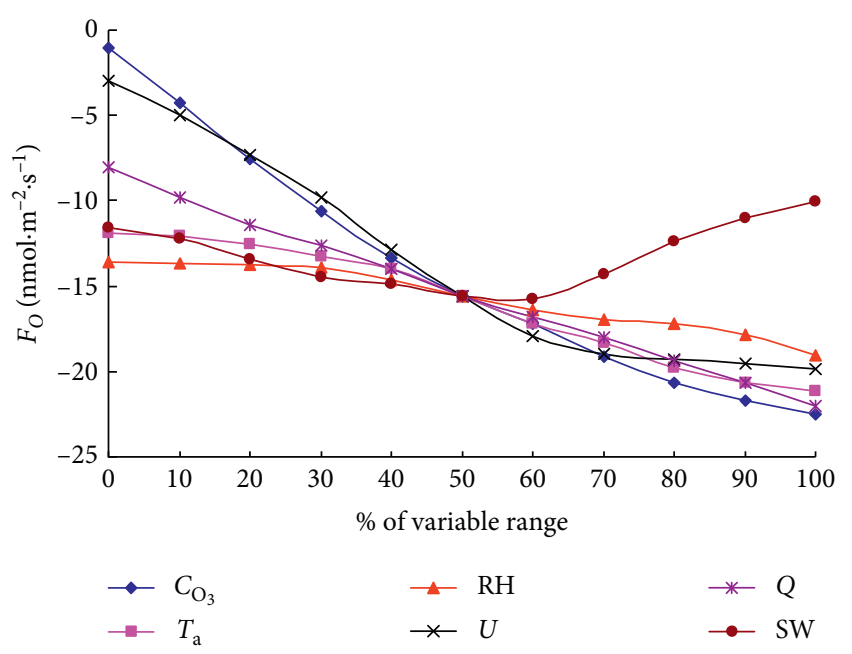

(a)

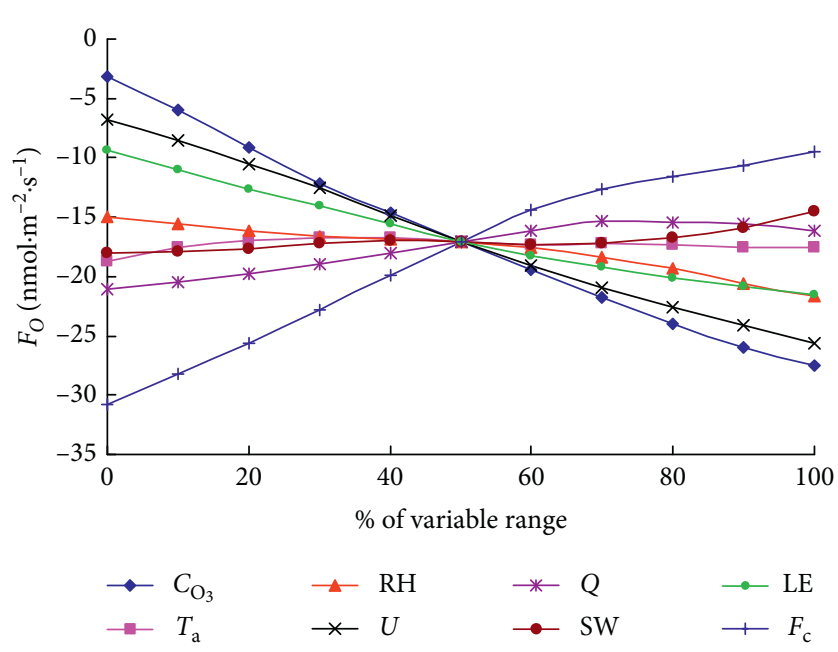

(b)

FIGURE 5: Responses and relative importance of each variable in the ANN models T15 and T20.

TABLE 3: Input parameters and their ranges for different models.

\begin{tabular}{lcccc}
\hline Variable & Unit & Min & Max & Mean \\
\hline Air temperature $\left(T_{\mathrm{a}}\right)$ & $\mathrm{C}$ & -5.4 & 30.6 & 12.6 \\
Relative humidity $(\mathrm{RH})$ & $\%$ & 14 & 100 & 57 \\
Wind speed $(U)$ & $\mathrm{m} \cdot \mathrm{s}^{-1}$ & 0 & 7.2 & 3.6 \\
Ozone concentration $\left(C_{\mathrm{O}_{3}}\right)$ & $\mathrm{Ppb}$ & 1.0 & 124.2 & 62.6 \\
Global radiation $(Q)$ & $\mathrm{W} \cdot \mathrm{m}^{-2}$ & 0 & 924 & 462 \\
Sensible heat flux $(H)$ & $\mathrm{W} \cdot \mathrm{m}^{-2}$ & -100 & 300 & 100 \\
Latent heat flux $(\mathrm{LE})$ & $\mathrm{W} \cdot \mathrm{m}^{-2}$ & 0 & 560 & 280 \\
$\mathrm{CO}_{2}$ flux $\left(F_{\mathrm{c}}\right)$ & $\mathrm{mg} \cdot \mathrm{m}^{2} \cdot \mathrm{s}^{-1}$ & -2.2 & 0.2 & -1.0 \\
\hline
\end{tabular}

content was too high or too low. The results might be unreliable and should be explained carefully. One possible reason for this pattern is that the change in soil water content is slow over the course of a day and there is no clear diurnal variation. The response of $S_{\mathrm{W}}$ and $F_{\mathrm{o}}$ in the ANN models mainly reflects the long-term variation of $\mathrm{O}_{3}$ flux. For other variables, the diurnal variation amplitude is larger than that of long-term variations. A simple expression that relates $F_{\mathrm{o}}$ and the various variables could not be given by the ANNs, as the response of $F_{\mathrm{o}}$ to a single variable may depend on the values of the other inputs. However, the response curves of variables can basically reflect the effect of each variable on $\mathrm{O}_{3}$ flux.

The response curve can also reveal the importance of each variable [41]. This method is called the "profile method" [25]. In this study, the importance of each variable is described by comparing the variation ranges of modeled values when a variable is varied from its minimum to maximum and other variables are fixed at their mean values given in Table 3. A larger variation in $F_{\mathrm{o}}$ indicates a higher parameter importance. Excluding the effects of fluxes, the order of variable importance in model $\mathrm{T} 15$ is as follows: $C_{\mathrm{O}_{3}}>U>Q>T_{\mathrm{a}}>\mathrm{RH}>S_{\mathrm{W}}$ (Figure $\left.5(\mathrm{a})\right) . \mathrm{O}_{3}$ concentration, wind speed, and radiation are the important factors affecting ozone deposition over wheat fields. In addition, to quantitatively reflect the effect of each variable, the relative importance (RI) of each variable was calculated $[39,49,50]$. The
RI of $C_{\mathrm{O}_{3}}, U, Q, T_{\mathrm{a}}, \mathrm{RH}$, and $S_{\mathrm{W}}$ are $26.7,21.6,20.6,12.4,11.3$ and 7.4 , respectively.

Using equation (2), it is easy to understand that the ozone concentration is the most important factor affecting ozone flux. Other factors controlling ozone deposition, such as solar radiation, temperature, humidity, and soil water content, have also been studied [47, 51]. Wind speed is another important factor affecting ozone deposition in this study. Although wind speed does not directly result in the increase of ozone deposition, it does enhance atmospheric turbulence. This causes more ozone in the air to enter crop stomata. In fact, radiation indirectly influences ozone deposition by influencing other model inputs. It results in the production of local ozone and leads to the changes in temperature, humidity, wind speed, and other environmental factors.

When considering the effects of fluxes, the order of variable importance in model T20 is as follows: $F_{\mathrm{c}}>C_{\mathrm{O}_{3}}>U>\mathrm{LE}>\mathrm{Q}>T_{\mathrm{a}}$ (Figure 5(b)). As most $\mathrm{CO}_{2}$ and water vapor are exchanged via the same pathway of stomata $[52,53]$, there are strong corrections between $F_{\mathrm{o}}$ and other gas fluxes $\left(F_{\mathrm{c}}\right.$ and LE). Stomatal uptake might play an important role in ozone deposition. In model T20, the effect of $Q$ on ozone flux becomes small. This might be because the effects of radiation are replaced by these fluxes. In other words, when the effects of $\mathrm{CO}_{2} / \mathrm{H}_{2} \mathrm{O}$ fluxes are taken into account, the correlations between $F_{\mathrm{o}}$ and these fluxes are more significant than those between $F_{\mathrm{o}}$ and radiation.

\section{Conclusions}

Based on the EC-measured $F_{\mathrm{o}}$ and other environmental factors over a wheat field, an artificial neural network method was attempted to simulate the relationships between $F_{\mathrm{o}}$ and environmental factors. Our conclusions can be summarized as follows:

(1) Generally, more input variables can increase the performance of a model. By only using the routine 
micrometeorological variables of radiation and $\mathrm{O}_{3}$ concentration, we can create an ANN model to simulate the variation of $F_{\mathrm{o}}$. The $R^{2}$ of a model with 6 routine independent variables can exceed 0.8 for the training dataset and test dataset. $\mathrm{CO}_{2}$ flux and water vapor flux have strong corrections to $F_{\mathrm{o}}$, and they can improve the fitness of the ANN models when they are considered as independent variables.

(2) In addition to variable combinations and training data, the model parameters (e.g., the number of neurons) are also a source of uncertainties in an ANN model. The effect of neuron number on our model fitness (MAE, RMSE, and $R^{2}$ ) is obvious when it changes from 1 to 10 . Empirically, one hidden layer with 17 neurons produced the best results.

(3) The ANN model is composed of complex arithmetic expressions between $F_{\mathrm{o}}$ and independent variables, an optimal ANN model can roughly reflect their inner relationships and relative importance. Global radiation, $\mathrm{O}_{3}$ concentration, and wind speed are the important factors that affect $\mathrm{O}_{3}$ deposition. There are strong correlations between $F_{\mathrm{o}}$ and gas fluxes $\left(F_{\mathrm{c}}\right.$ and $\mathrm{LE})$. The ANN method represents a valuable route for filling the gaps of a time series of $F_{\mathrm{o}}$ during the experimental period with micrometeorological methods.

\section{Data Availability}

The MS-Excel data used to support the findings of this study are available from the corresponding author upon request.

\section{Conflicts of Interest}

The authors declare that they have no conflicts of interest.

\section{Acknowledgments}

This work was supported by the National Natural Science Foundation of China (grant number 41675147) and the National Key R\&D program of China (grant number 2017YFC0503801). The author would also like to thank Accdon for providing linguistic assistance during the preparation and revision of this manuscript.

\section{References}

[1] R. A. Kerr, "Ozone depletion: a brighter outlook for good ozone,” Science, vol. 297, no. 5587, pp. 1623-1625, 2002.

[2] X. Wang, Q. Zhang, F. Zheng et al., "Effects of elevated O3 concentration on winter wheat and rice yields in the Yangtze River Delta, China," Environmental Pollution, vol. 171, pp. 118-125, 2012.

[3] P. J. Crutzen, M. G. Lawrence, and U. Poschl, "On the background photochemistry of tropospheric ozone," Tellus A, vol. 51, no. 1, pp. 123-146, 1999.

[4] W. J. Massman, "Toward an ozone standard to protect vegetation based on effective dose: a review of deposition resistances and a possible metric," Atmospheric Environment, vol. 38, no. 15, pp. 2323-2337, 2004.
[5] E. Paoletti and W. J. Manning, "Toward a biologically significant and usable standard for ozone that will also protect plants," Environmental Pollution, vol. 150, no. 1, pp. 85-95, 2007.

[6] R. Musselman, A. Lefohn, W. Massman, and R. Heath, "A critical review and analysis of the use of exposure- and fluxbased ozone indices for predicting vegetation effects," Atmospheric Environment, vol. 40, no. 10, pp. 1869-1888, 2006.

[7] H. Pleijel, H. Danielsson, K. Ojanperä et al., "Relationships between ozone exposure and yield loss in European wheat and potato-a comparison of concentration- and flux-based exposure indices," Atmospheric Environment, vol. 38, no. 15, pp. 2259-2269, 2004.

[8] G. Gerosa, S. Cieslik, and A. Ballarin-Denti, "Micrometeorological determination of time-integrated stomatal ozone fluxes over wheat: a case study in Northern Italy," Atmospheric Environment, vol. 37, no. 6, pp. 777-788, 2003.

[9] D. Fowler, C. Flechard, J. N. Cape, R. L. Storeton-West, and M. Coyle, "Measurements of ozone deposition to vegetation quantifying the flux, the stomatal and non-stomatal components," Water, Air, and Soil Pollution, vol. 130, no. 1-4, pp. 63-74, 2001.

[10] D. D. Baldocchi, "Measuring fluxes of trace gases and energy between ecosystems and the atmosphere-the state and future of the eddy covariance method," Global Change Biology, vol. 20, no. 12, pp. 3600-3609, 2014.

[11] E. Lamaud, A. Carrara, Y. Brunet, A. Lopez, and A. Druilhet, "Ozone fluxes above and within a pine forest canopy in dry and wet conditions," Atmospheric Environment, vol. 36, no. 1, pp. 77-88, 2002.

[12] E. Lamaud, B. Loubet, M. Irvine, P. Stella, E. Personne, and P. Cellier, "Partitioning of ozone deposition over a developed maize crop between stomatal and non-stomatal uptakes, using eddy-covariance flux measurements and modelling," Agricultural and Forest Meteorology, vol. 149, no. 9, pp. 1385-1396, 2009.

[13] T. N. Mikkelsen, H. Ro-Poulsen, M. F. Hovmand, N. O. Jensen, K. Pilegaard, and A. H. Egeløv, "Five-year measurements of ozone fluxes to a Danish Norway spruce canopy," Atmospheric Environment, vol. 38, no. 15, pp. 2361-2371, 2004.

[14] Z. Zhu, F. Zhao, L. Voss et al., "The effects of different calibration and frequency response correction methods on eddy covariance ozone flux measured with a dry chemiluminescence analyzer," Agricultural and Forest Meteorology, vol. 213, pp. 114-125, 2015.

[15] E. Falge, D. Baldocchi, R. Olson et al., "Gap filling strategies for defensible annual sums of net ecosystem exchange," Agricultural and Forest Meteorology, vol. 107, no. 1, pp. 43-69, 2001.

[16] A. M. Moffat, D. Papale, M. Reichstein et al., "Comprehensive comparison of gap-filling techniques for eddy covariance net carbon fluxes," Agricultural and Forest Meteorology, vol. 147, no. 3-4, pp. 209-232, 2007.

[17] M. L. Wesely, "Parameterization of surface resistances to gaseous dry deposition in regional-scale numerical models," Atmospheric Environment, vol. 23, no. 6, pp. 1293-1304, 1989.

[18] L. Zhang, J. R. Brook, and R. Vet, "On ozone dry depositionwith emphasis on non-stomatal uptake and wet canopies," Atmospheric Environment, vol. 36, no. 30, pp. 4787-4799, 2002.

[19] M. Aubinet, A. Grelle, A. Ibrom et al., "Estimates of the annual net carbon and water exchange of forests: the EUROFLUX 
methodology," Andvances in Ecological Research, vol. 30, pp. 113-175, 2000.

[20] M. W. Gardner and S. R. Dorling, "Artificial neural networks (the multilayer perceptron)-a review of applications in the atmospheric sciences," Atmospheric Environment, vol. 32, no. 14-15, pp. 2627-2636, 1998.

[21] D. Papale and R. Valentini, "A new assessment of European forests carbon exchanges by eddy fluxes and artificial neural network spatialization," Global Change Biology, vol. 9, no. 4, pp. 525-535, 2003.

[22] G. R. Balls, D. Palmer-brown, and G. E. Sanders, "Investigating microclimatic influences on ozone injury in clover (Trifolium subterraneum) using artificial neural networks," New Phytologist, vol. 132, no. 2, pp. 271-280, 1996.

[23] A. C. Comrie, "Comparing neural networks and regression models for ozone forecasting," Journal of the Air and Waste Management Association, vol. 47, no. 6, pp. 653-663, 1997.

[24] J. M. Nicely, R. J. Salawitch, T. Canty et al., "Quantifying the causes of differences in tropospheric $\mathrm{OH}$ within global models," Journal of Geophysical Research: Atmospheres, vol. 122, no. 3, pp. 1983-2007, 2017.

[25] M. Gevrey, I. Dimopoulos, and S. Lek, "Review and comparison of methods to study the contribution of variables in artificial neural network models," Ecological Modelling, vol. 160, no. 3, pp. 249-264, 2003.

[26] J. A. Vrugt, W. Bouten, S. C. Dekker, and P. A. D. Musters, "Transpiration dynamics of an Austrian pine stand and its forest floor: identifying controlling conditions using artificial neural networks," Advances in Water Resources, vol. 25, no. 3, pp. 293-303, 2002.

[27] Y. Feng, W. Zhang, D. Sun, and L. Zhang, "Ozone concentration forecast method based on genetic algorithm optimized back propagation neural networks and support vector machine data classification," Atmospheric Environment, vol. 45, no. 11, pp. 1979-1985, 2011.

[28] J. C. M. Pires, B. Gonçalves, F. G. Azevedo et al., "Optimization of artificial neural network models through genetic algorithms for surface ozone concentration forecasting," Environmental Science and Pollution Research, vol. 19, no. 8, pp. 3228-3234, 2012.

[29] H. He, G. Yu, L. Zhang, X. Sun, and W. Su, "Simulating CO2 flux of three different ecosystems in ChinaFLUX based on artificial neural networks," Science in China Series D: Earth Sciences, vol. 49, no. S2, pp. 252-261, 2006.

[30] M. T. V. Wijk and W. Bouten, "Water and carbon fluxes above european coniferous forests modelled with artificial neural networks," Ecological Modelling, vol. 120, pp. 181-197, 1999.

[31] A. Zahn, J. Weppner, H. Widmann et al., "A fast and precise chemiluminescence ozone detector for eddy flux and airborne application," Atmospheric Measurement Techniques, vol. 5, no. 2, pp. 363-375, 2012.

[32] M. Ermel, R. Oswald, J.-C. Mayer et al., "Preparation methods to optimize the performance of sensor discs for fast chemiluminescence ozone analyzers," Environmental Science and Technology, vol. 47, no. 4, pp. 1930-1936, 2013.

[33] J. B. A. Muller, C. J. Percival, M. W. Gallagher, D. Fowler, M. Coyle, and E. Nemitz, "Sources of uncertainty in eddy covariance ozone flux measurements made by dry chemiluminescence fast response analysers," Atmospheric Measurement Techniques, vol. 3, no. 1, pp. 163-176, 2010.

[34] J. M. Wilczak, S. P. Oncley, and S. A. Stage, "Sonic anemometer tilt correction algorithms," Boundary-Layer Meteorology, vol. 99, no. 1, pp. 127-150, 2001.
[35] J. B. Moncrieff, J. M. Massheder, H. De Bruin et al., “A system to measure surface fluxes of momentum, sensible heat, water vapour and carbon dioxide," Journal of Hydrology, vol. 188189, pp. 589-611, 1997.

[36] E. Webb, G. Pearman, and R. Leuning, "Correction of flux measurements for density effects due to heat and water vapour transfer," Quarterly Journal of the Royal Meteorological Society, vol. 106, no. 447, pp. 85-100, 1980.

[37] C. Huntingford and P. M. Cox, "Use of statistical and neural network techniques to detect how stomatal conductance responds to changes in the local environment," Ecological Modelling, vol. 97, no. 3, pp. 217-246, 1997.

[38] S. Lek, J. L. Giraudel, and J. P. Guegan, "Neuronal networks. Algorithms and architectures for ecologists and evolutionary ecologists," in Artificial Neuronal Network: Application to Ecology and Evolution, S. Lek and J. P. Guegan, Eds., SpringerVerlag Berlin, Heidelberg, New York, NY, USA, 2000.

[39] X. Dai, Z. Huo, and H. Wang, "Simulation for response of crop yield to soil moisture and salinity with artificial neural network," Field Crops Research, vol. 121, no. 3, pp. 441-449, 2011.

[40] G. Zhang, B. Eddy Patuwo, and Y. Hu M., "Forecasting with artificial neural networks:," International Journal of Forecasting, vol. 14, no. 1, pp. 35-62, 1998.

[41] S. Lek, M. Delacoste, P. Baran, I. Dimopoulos, J. Lauga, and S. Aulagnier, "Application of neural networks to modelling nonlinear relationships in ecology," Ecological Modelling, vol. 90, no. 1, pp. 39-52, 1996.

[42] G. Gerosa, R. Marzuoli, S. Cieslik, and A. Ballarin-Denti, "Stomatal ozone fluxes over a barley field in Italy. "Effective exposure" as a possible link between exposure- and flux-based approaches," Atmospheric Environment, vol. 38, no. 15, pp. 2421-2432, 2004.

[43] H. Akimoto, "Global air quality and pollution," Science, vol. 302, no. 5651, pp. 1716-1719, 2003.

[44] J. N. Cape, "Surface ozone concentrations and ecosystem health: past trends and a guide to future projections," Science of the Total Environment, vol. 400, no. 1-3, pp. 257-269, 2008.

[45] C. Dueñas, M. C. Fernández, S. Cañete, J. Carretero, and E. Liger, "Assessment of ozone variations and meteorological effects in an urban area in the Mediterranean Coast," Science of The Total Environment, vol. 299, no. 1-3, pp. 97-113, 2002.

[46] S. Fares, R. Weber, J.-H. Park, D. Gentner, J. Karlik, and A. H. Goldstein, "Ozone deposition to an orange orchard: partitioning between stomatal and non-stomatal sinks," Environmental Pollution, vol. 169, pp. 258-266, 2012.

[47] A. A. Turnipseed, S. P. Burns, D. J. P. Moore, J. Hu, A. B. Guenther, and R. K. Monson, "Controls over ozone deposition to a high elevation subalpine forest," Agricultural and Forest Meteorology, vol. 149, no. 9, pp. 1447-1459, 2009.

[48] M. Wesely and B. B. Hicks, "A review of the current status of knowledge on dry deposition," Atmospheric Environment, vol. 34, no. 12-14, pp. 2261-2282, 2000.

[49] A. Alimissis, K. Philippopoulos, C. G. Tzanis, and D. Deligiorgi, "Spatial estimation of urban air pollution with the use of artificial neural network models," Atmospheric Environment, vol. 191, pp. 205-213, 2018.

[50] C. G. Tzanis, A. Alimissis, K. Philippopoulos, and D. Deligiorgi, "Applying linear and nonlinear models for the estimation of particulate matter variability," Environmental Pollution, vol. 246, pp. 89-98, 2019.

[51] D. Fowler, K. Pilegaard, M. A. Sutton et al., "Atmospheric composition change: ecosystems-Atmosphere interactions," 
Atmospheric Environment, vol. 43, no. 33, pp. 5193-5267, 2009.

[52] S. Fares, A. Conte, and A. Chabbi, "Ozone flux in plant ecosystems: new opportunities for long-term monitoring networks to deliver ozone-risk assessments," Environmental Science and Pollution Research, vol. 25, no. 9, pp. 8240-8248, 2018.

[53] G. Gerosa, F. Derghi, and S. Cieslik, "Comparison of different algorithms for stomatal ozone flux determination from micrometeorological measurements," Water, Air, and Soil Pollution, vol. 179, no. 1-4, pp. 309-321, 2007. 

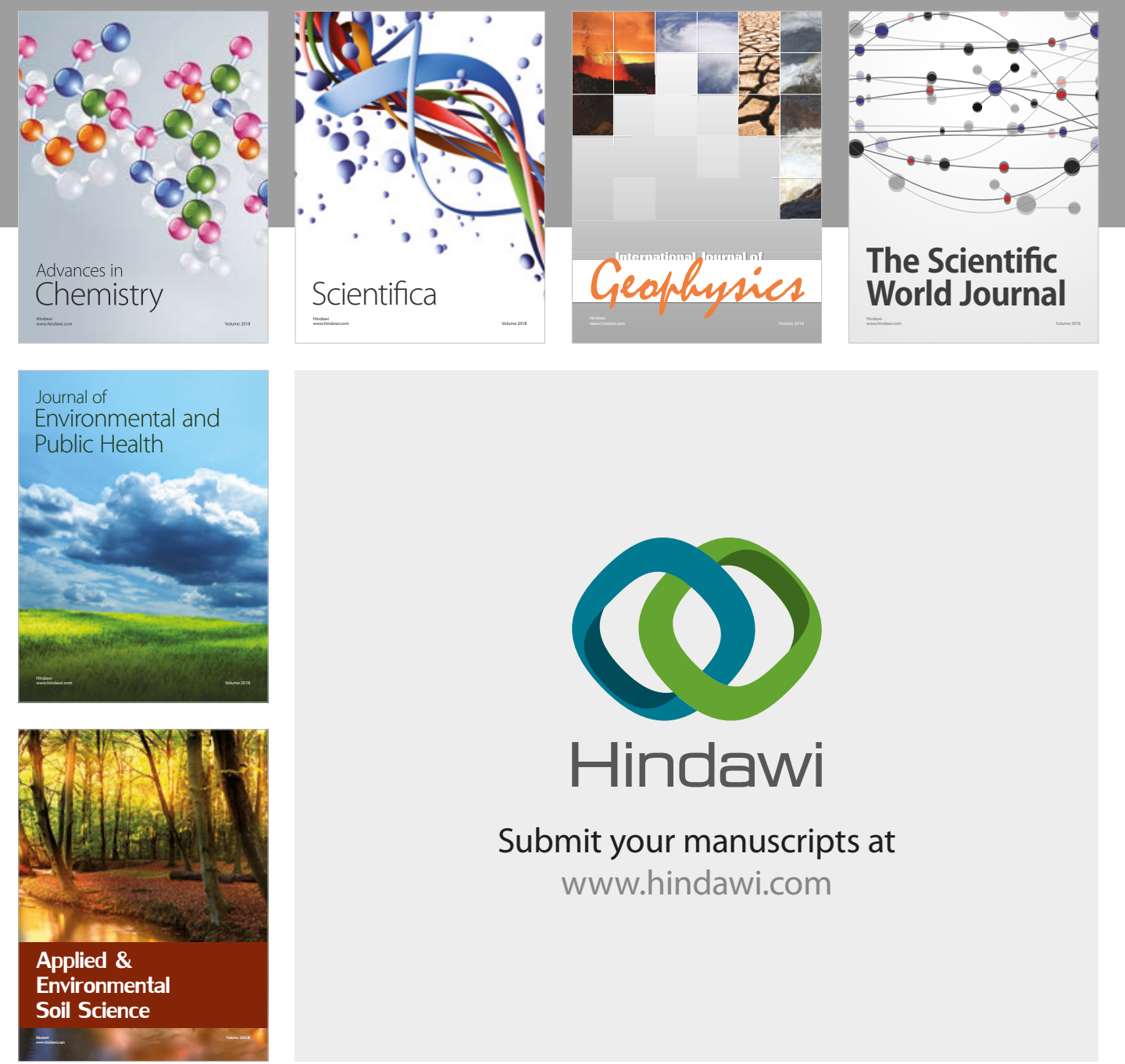

The Scientific

\section{World Journal}
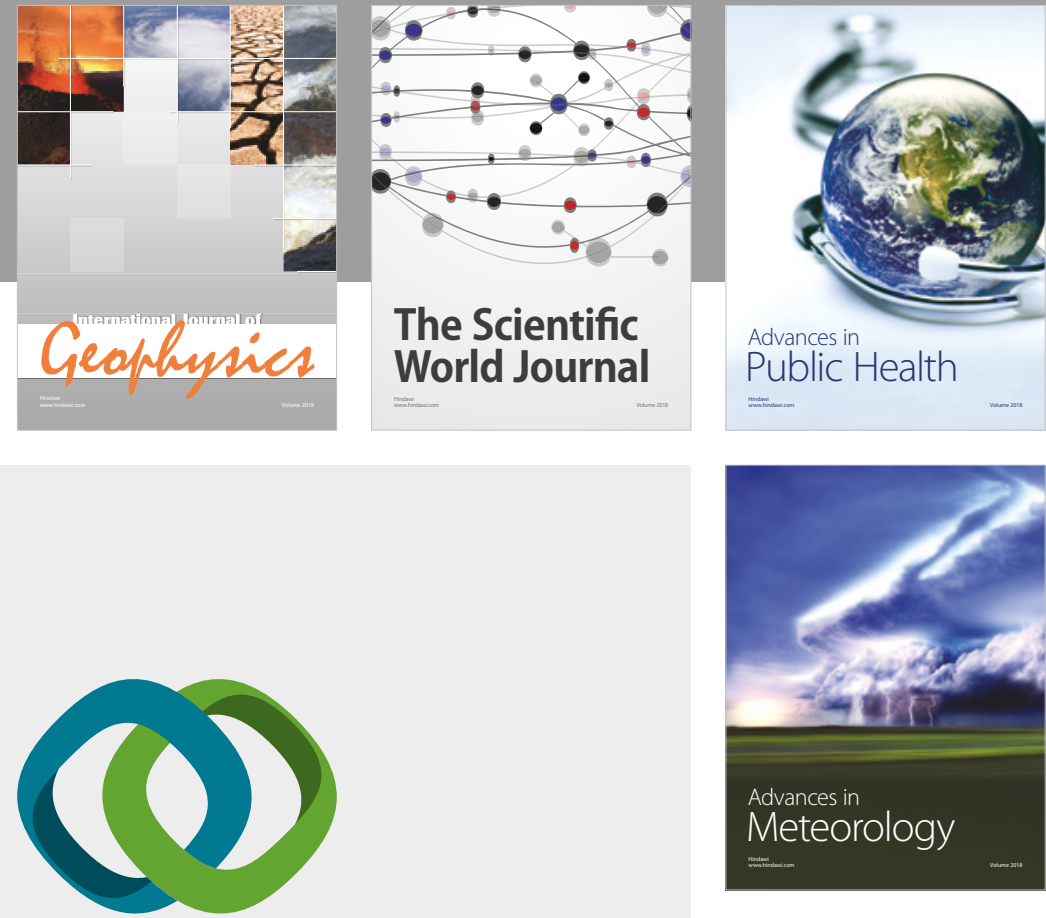

Advan

Public Health

\section{Hindawi}

Submit your manuscripts at

www.hindawi.com
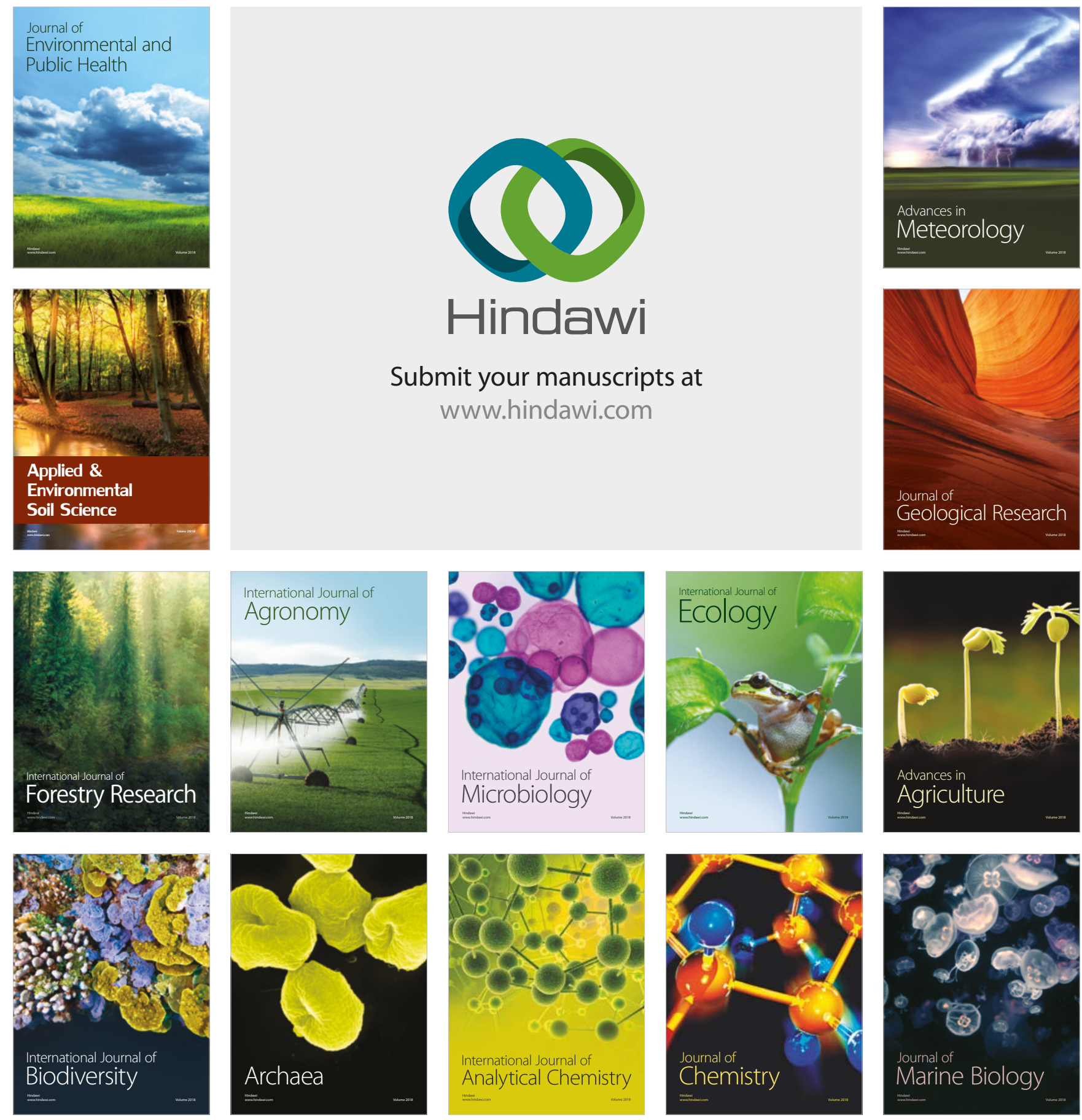